\title{
PENGARUH EMPLOYEE WELL-BEING DAN JOB SATISFACTION TERHADAP EMPLOYEE PERFORMANCE
}

\author{
Ariesto Patria Sabil \\ Universitas Negeri Surabaya \\ Ariesto.17080574142@mhs.unesa.ac.id
}

\begin{abstract}
In this globalization era, every corporation works hard to increase and develop to boost their employee performance. There are lot of factors corporation has to take care to increase their employee performance. This research probes employee well-being and job satisfaction as independent variables to employee performance as dependent variables. The selection method of the sample is using purposive sampling and obtained 95 samples from the population of the whole employee of the corporation using a questionnaire to collect the samples.SPSS 26 from IBM is being used for the multiple linear regression analysis techniques. A significant and positive effect is discovered from job satisfaction to employee performance, while employee well-being has a nonsignificant effect. The company should consider their employee job satisfaction in order to increase company's performance.
\end{abstract}

Keywords: employee performance; employee well-being; job satisfaction.

\section{PENDAHULUAN}

Perusahaan di era modern bekerja keras untuk membangun rencana peningkatan kinerja karyawan dengan banyak cara dalam rangka peningkatan dan pengembangan perusahaan. Banyak faktor yang dapat memengaruhi peningkatan kinerja perusahaan dalam memeroleh keuntungan dengan mewujudkan visi dan misi tertentu (Qustolani, 2017). Sumber daya manusia berperan penting dalam menumbuhkan ekonomi di suatu negara. Bila kesejahteraan karyawan dan kepuasan kerja tidak diterapkan di dalam perusahaan, maka hal tersebut berpotensi berpengaruh terhadap kinerja para karyawan yang kurang maksimal. Manajemen suatu perusahaan dapat dikatakan berhasil apabila dilihat dari status pegawai atau sumber daya manusianya. Perusahaan sering kali menghadapi masalah sumber daya manusia yang terkadang menjadi kendala dalam upaya mencapai tujuan. Jika sumber daya manusia berjalan dengan baik dan efektif dalam melaksanakan pekerjaannya, maka keberhasilan perusahaan juga akan efektif. Peningkatan kinerja karyawan berperan terhadap kemajuan bagi suatu perusahaan atau organisasi untuk dapat bertahan dalam lingkungan yang tidak sehat. Maka, upaya peningkatan kinerja karyawan merupakan tantangan besar bagi manajemen dikarenakan keberhasilan dalam mencapai tujuan organisasi dan kelangsungan hidup tergantung pada kualitas kinerja sumber daya manusia di dalam perusahaan (Dedik, 2019). Masyitah \& Harahap (2018) mendefinisikan kinerja adalah luaran yang dihasilkan oleh seseorang atau karyawan saat melakukan suatu pekerjaan atau mencapai keberhasilan seseorang dalam mencapai tujuan dalam pekerjaannya.

Seorang karyawan tentunya memiliki keinginan untuk memeroleh sesuatu yang sesuai. Kesejahteraan karyawan adalah imbalan selain upah dan gaji (kompensasi langsung), atau bentuk pembayaran langsung (kompensasi tidak langsung atau disebut juga bonus) yang diberikan kepada seorang karyawan dan pasalnya tidak didasarkan pada kinerja karyawan tetapi didasarkan pada keanggotaannya dalam organisasi sebagai bagian dari suatu organisasi dan keberadannya sebagai pribadi yang utuh yang berguna dalam memenuhi kebutuhan karyawan selain gaji (Ni'mah, 2016). Kesejahteraan karyawan perusahaan atau organisasi adalah hal esensial yang perlu diperhatikan perusahaan. Kesejahteraan karyawan yang diberikan sangat berarti dan membantu dalam pemenuhan kebutuhan fisik maupun psikis karyawan serta keluarganya. Kesejahteraan karyawan adalah kompensasi tambahan (materiil dan non materiil) yang adil dan layak dalam upaya memberikan motivasi kepada karyawan untuk meningkatkan kinerjanya dengan tujuan memelihara dan meningkatkan kondisi fisik dan psiskis karyawan agar prestasi kerjanya dapat meningkat (Subardjono, 2017). 
Kepuasan kerja merupakan cerminan dari rasa pekerjaan seseorang. Ini adalah hasil dari etos kerja yang baik dari kelas pekerja dan segala sesuatu yang terjadi pada mereka di dunia kerja (Maulidiyah et al., 2021). Lingkungan kerja akan meningkatkan dan mendukung pekerjaan karyawan di tempat kerja, sehingga mereka merasa nyaman dalam kinerja pekerjaannya dan kepuasan atas pekerjaan yang dilakukan. Hubungan yang baik antara eksekutif senior dan bawahan dapat menjadi penyebab utama ketidakpuasan kerja. Untuk menghindari gejala tersebut dapat dilakukan dengan membicarakan masalah secara terbuka, sehingga komunikasi yang baik antara pejabat atas dan bawah diharapkan dapat membantu dalam pencapaian tujuan organisasi (Sujati, 2018). Kepuasan kerja adalah sekumpulan karyawan yang merasa bahwa pekerjaannya menyenangkan atau tidak (Muayyad \& Gawi, 2017). Kepuasan kerja dapat dilihat pada sikap karyawan. Hal ini mengindikasikan hubungan antara ekspektasi karyawan dalam kepuasan kerja serta kompensasi yang ditawarkan pekerjaan tersebut (Mandala \& Dihan, 2018)

Berdasarkan informasi dari bagian humas PT. PAL Indonesia, terjadi perubahan yang cukup signifikan di lingkungan kerja dikarenakan adanya pandemi serta adanya sistem perusahaan yang menerapkan kedisiplinan dengan tingkat tinggi. Dengan ini kesejahteraan karyawan dan kepuasan kerja perlu dipertanyakan. Penelitian ini bertujuan untuk menemukan pengaruh employee well-being dan job satisfaction terhadap employee performance pada karyawan.

\section{KAJIAN PUSTAKA DAN PENGEMBANGAN HIPOTESIS}

\section{Employee Well-Being}

Employee well-being merupakan kesatuan dari kesejahteraan individu atas sebuah pekerjaan yang dipengaruhi oleh lingkungan kerja (Rizky \& Sadida, 2019). Menurut Purba (2019), employee wellbeing adalah hak karyawan atau kelompok karyawan atas bagian keanggotaan mereka dalam organisasi berupa penghargaan tak langsung. Employee well-being dapat dikatakan sebagai keseimbangan antara upaya yang dilakukan karyawan dan kompensasi yang mereka dapatkan. Kurangnya keseimbangan antara keduanya menyebabkan rendahnya kesejahteraan pada karyawan (Sadida \& Fitria, 2018). Penelitian ini menggunakan indikator dari Hasibuan (2016) yang telah mengembangkan indikator employee wellbeing yaitu: kesejahteraan bersifat ekonomis, kesejahteraan yang menopang seperti fasilitas ibadah, cuti, dan izin, serta kesejahteraan yang bersifat pelayanan seperti jaminan kesehatan dan kredit rumah.

\section{Job Satisfaction}

Job satisfaction adalah situasi mental, fisiologis dan lingkungan yang merangsang seseorang untuk mengekspresikan kepuasan kerja (Saleem, 2015). Menurut Badriyah (2015), job satisfaction merupakan sikap atau perasaan karyawan terhadap aspek pekerjaan yang menyenangkan maupun sebaliknya menurut penilaian masing-masing karyawan. Job satisfaction mengacu pada sikap umum seorang individu terhadap pekerjaan yang mereka lakukan. Seseorang dengan tingkat kepuasan kerja yang tinggi menunjukkan sikap yang positif terhadap pekerjaannya, sebaliknya seseorang yang tidak puas dengan pekerjaannya menunjukkan sikap negatif terhadap pekerjaannya (Maulidiyah et al., 2021). Penelitian ini menggunakan indikator job satisfaction dari Cekmecelioglu et al. (2012) antara lain: kepuasan atas kerja, kompensasi, kesempatan atas promosi.

\section{Employee Performance}

Kinerja merupakan hasil berupa kualitas dan kuantitas atas pekerjaan yang dilakukan karyawan dalam melaksanakan tanggung jawab (Damayanti et al., 2018). Kinerja karyawan merupakan keadaan lengkap dari perubahan atas periode tertentu, merupakan hasil atau prestasi yang dipengaruhi oleh kegiatan operasional perusahaan dalam penggunaan sumber daya yang tersedia (Hustia, 2020). Menurut Fachreza et al. (2018), kinerja karyawan merupakan luaran atas pencapaian oleh seorang individu atau sekelompok individu dalam suatu organisasi guna mencapai tujuan organisasi sesuai dengan tanggung jawab dan wewenangnya masing-masing. Menurut Robbins \& Mary (2012), terdapat lima indikator ukuran kinerja individual karyawan, antara lain: kualitas yang diukur menggunakan sudut pandang karyawan atas kualitas maupun kesempurnaan tugas ditinjau dari kemampuan dan keterampilannya, kuantitas yang diukur secara jumlah atas luaran atau hasil 
pekerjaan karyawan ditinjau dari kemampuan dan keterampilannya, ketepatan waktu penyelesaian pekerjaan yang ditinjau dari koordinasi luaran dengan efisiensi waktu untuk kegiatan lainnya, efektivitas pekerjaan dengan memanfaatkan efisiensi sumber daya sesuai dengan pesanan, dan kemandirian karyawan dalam menjalankan kemampuan profesionalnya dan komitmen untuk bekerja.

\section{Hubungan antar Variabel}

Wadhawan (2016) menjelaskan bahwa employee well-being memiliki pengaruh positif signifikan terhadap kinerja karyawan yang menunjukkan bahwa penerapan kesejahteraan karyawan di dalam perusahaan berbanding lurus dengan kinerja karyawan. Penelitian Jalali \& Heidari (2016) menunjukkan pengaruh positif signifikan pada employee well-being terhadap employee performance. Pada penelitian Kundi et al. (2020), hasil menunjukkan bahwa employee well-being dan employee performance memiliki pengaruh positif dan signifikan. Jadi, bagaimana karyawan diperlakukan dan menerima imbal balik dari kinerjanya memengaruhi bagaimana karyawan melaksanakan tugas dan tanggung jawabnya yang berimplikasi pada kinerja.

H1: Employee well-being berpengaruh positif signifikan terhadap employee performance.

Permadi et al. (2018) menunjukkan bahwa employee performance dipengaruhi secara positif signifikan oleh job satisfaction. Mandala \& Dihan (2018) dalam penelitiannya menemukan bahwa job satisfaction memiliki pengaruh signifikan positif terhadap employee performance. Namun, hasil penelitian Sari (2020) menunjukkan bahwa pengaruh job satisfaction terhadap employee performance berpengaruh negatif dan tidak signifikan. Jadi, ada keterkaitan antara kepuasan kerja yang dirasakan oleh karyawan dalam melaksanakan tugas dan tanggung jawabnya terhadap kinerja mereka.

H2: Job satisfaction berpengaruh positif signifikan terhadap employee performance.

Gambar 1 mengilustrasikan pengaruh antar variabel secara keseluruhan.

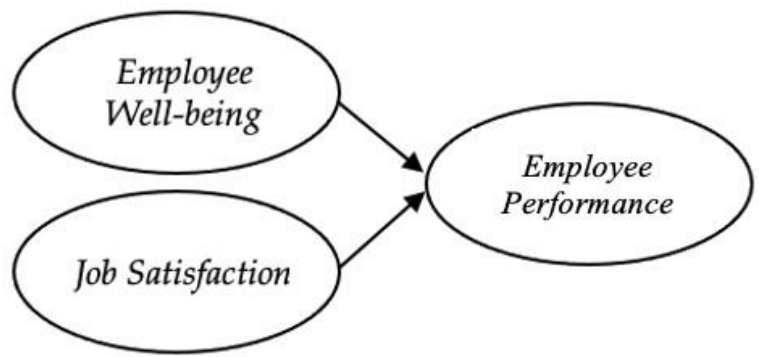

Gambar 1. MODEL PENELITIAN

\section{METODE PENELITIAN}

Jenis penelitian ini adalah kausal kuantitatif dengan mencari keterkaitan antar variabel. Penelitian ini dilakukan pada PT. PAL Indonesia (Persero). Random sampling digunakan sebagai metode penentuan sampel dalam penelitian ini. Seluruh karyawan PT. PAL Indonesia (Persero) adalah total populasi dengan jumlah 1000 karyawan dengan ukuran sampel yang ditetapkan sejumlah 95 sampel menggunakan rumus slovin. Pengumpulan data dilakukan dengan cara pemberian kuesioner pada karyawan PT. PAL Indonesia (Persero) dengan menggunakan skala Likert dari 1 sampai 5 sebagai skala pengukuran dalam tolok ukur instrumen penelitian. Teknik analisis data menggunakan multiple linear regression. Data diolah dengan program IBM SPSS Statistics 26.

\section{HASIL DAN PEMBAHASAN}

\section{Hasil Uji Statistik}

Sebelum melakukan uji regresi linier berganda untuk mengetahui pengaruh antara variabel dependen dengan variabel independen, uji instrumen yang meliputi validitas dan reliabilitas terlebih dahulu 
Ariesto Patria Sabil. Pengaruh Employee Well-being dan Job Satisfaction terhadap Employee Performance

dilakukan. Kemudian dilakukan uji asumsi klasik yang meliputi normalitas; heteroskedasitas; dan multikolinieritas juga sebagai persyaratan sebelum menguji pengaruh.

\section{Uji Validitas}

Tabel 1 menunjukkan hasil uji validitas dengan hasil masing-masing indikator yang memiliki nilai $r$ hitung > r tabel yaitu 0,197. Maka, setiap instrumen dinyatakan valid dalam mengukur jawaban para responden dari obyek penelitian.

Tabel 1.

HASIL UJI VALIDITAS DAN RELIABILITAS

\begin{tabular}{|c|c|c|c|c|}
\hline Dimensi & Item & r Hitung & $r$ tabel & Cronbach's Alpha \\
\hline \multirow{4}{*}{ Economics } & $\mathrm{x} 1.1$ & 0,714 & \multirow{34}{*}{0,197} & \multirow{34}{*}{0,961} \\
\hline & x1.2 & 0,866 & & \\
\hline & x1.3 & 0,714 & & \\
\hline & x1.4 & 0,739 & & \\
\hline \multirow{7}{*}{ Facility } & x1.5 & 0,495 & & \\
\hline & x1.6 & 0,672 & & \\
\hline & x1.7 & 0,744 & & \\
\hline & x1.8 & 0,692 & & \\
\hline & $\mathrm{x} 1.9$ & 0,859 & & \\
\hline & $\mathrm{x} 1.10$ & 0,866 & & \\
\hline & $\mathrm{x} 1.11$ & 0,604 & & \\
\hline \multirow{4}{*}{ Services } & $\mathrm{x} 1.12$ & 0,866 & & \\
\hline & $\mathrm{x} 1.13$ & 0,565 & & \\
\hline & $\mathrm{x} 1.14$ & 0,755 & & \\
\hline & $\mathrm{x} 1.15$ & 0,666 & & \\
\hline \multirow{2}{*}{ The Work Itself } & $\mathrm{x} 2.1$ & 0,704 & & \\
\hline & $\mathrm{x} 2.2$ & 0,617 & & \\
\hline \multirow{2}{*}{ Pay } & $\mathrm{x} 2.3$ & 0,636 & & \\
\hline & x2.4 & 0,62 & & \\
\hline Promotion & x2.5 & 0,704 & & \\
\hline Opportunities & x2.6 & 0,632 & & \\
\hline \multirow{3}{*}{ Work Relation } & x2.7 & 0,866 & & \\
\hline & $\mathrm{x} 2.8$ & 0,672 & & \\
\hline & y1.1 & 0,529 & & \\
\hline \multirow[t]{2}{*}{ Work Quality } & y1.2 & 0,608 & & \\
\hline & y1.3 & 0,477 & & \\
\hline \multirow{2}{*}{ Work Quantity } & y1.4 & 0,549 & & \\
\hline & $\mathrm{y} 1.5$ & 0,46 & & \\
\hline \multirow{2}{*}{ Punctuality } & y1.6 & 0,53 & & \\
\hline & y1.7 & 0,696 & & \\
\hline \multirow{2}{*}{ Effectivity } & y1.8 & 0,704 & & \\
\hline & y1.9 & 0,491 & & \\
\hline \multirow{2}{*}{ Independency } & y1.10 & 0,558 & & \\
\hline & $\mathrm{y} 1.11$ & 0,558 & & \\
\hline
\end{tabular}

Sumber: Output SPSS (2021, data diolah)

\section{Uji Reliabilitas}

Tabel 1 menunjukkan nilai cronbach's alpha sebesar 0,961 > 0,7. Sehingga, setiap variabel pada penelitian ini dinyatakan reliabel untuk menjadi instrumen dalam memeroleh data sampel dari obyek penelitian.

\section{Uji Normalitas}

Hasil pada tabel 2 menggunakan uji Kolmogorov-smirnov pada masing-masing variabel menunjukkan nilai sig. $>0,05$. Nilai uji menunjukkan bahwa data sampel penelitian ini berdistribusi normal. 
Tabel 2.

UJI NORMALITAS, HETEROSKEDASITAS, DAN MULTIKOLINIERITAS

\begin{tabular}{|c|c|c|c|c|}
\hline Model & K-S (Sig.) & Tolerance & VIF & Gletser (Sig.) \\
\hline EP & 0,52 & & & - \\
\hline EWB & 0,61 & 0,279 & 3,578 & 0,161 \\
\hline JS & 0,51 & & & 0,053 \\
\hline
\end{tabular}

Sumber: Output SPSS (2021, data diolah)

\section{Uji Heteroskedasitas}

Hasil pada tabel 2 menggunakan Uji Glejser pada masing-masing variabel independen menunjukkan nilai sig. > 0,05. Nilai Uji Glejser menunjukkan bahwa data sampel tidak memiliki gejala heteroskedasitas.

\section{Uji Multikolinieritas}

Dari nilai tolerance dan VIF pada tabel 2 menunjukkan bahwa masing-masing variabel memiliki nilai tolerance $0,279>0,1$ dan nilai VIF 3,578 $<10$. Dari hasil uji statistik tersebut, data sampel penelitian ini tidak memiliki gejala multikolinieritas.

\section{Uji Regresi Linier Berganda}

Tabel 3 menunjukkan nilai uji regresi linier berganda dengan persamaan regresi (1). Didapatkan nilai konstanta 20,615 satuan dengan arti employee performance sebesar 20,615 satuan apabila seluruh variabel bernilai konstan. Koefisien regresi job satisfaction sebesar 0,828 dengan arti setiap peningkatan job satisfaction, maka employee performance akan meningkat 0,828 satuan.

$Y=20,615+0,828 J S+\mathrm{e}$

\section{Tabel 3.}

HASIL UJI REGRESI LINIER BERGANDA, UJI F, UJI T, DAN DETERMINASI

\begin{tabular}{lcrl}
\hline \multicolumn{1}{c}{ Model } & Koefisien & \multicolumn{1}{c}{ t } & sig \\
\hline (Constant $)$ & 20,615 & 6,082 & 0,000 \\
EWB & $-0,09$ & $-0,659$ & 0,512 \\
JS & 0,828 & 6,075 & 0,000 \\
F test & 54,649 & - & 0,000 \\
Adj. $R$ Squared & - & - & 0,533 \\
\hline \multicolumn{2}{l}{ Sumber: Output SPSS (2021, data diolah) }
\end{tabular}

\section{Uji Statistik F}

Tabel 3 menunjukkan angka $\mathrm{F}$ hitung adalah 54,649 dengan nilai probabilitas 0,000. Jadi, keseluruhan variabel yang memengaruhi employee performance secara simultan terbukti berpengaruh.

\section{Uji Statistik t}

Tabel 3 menyajikan angka t hitung variabel job satisfaction sebesar 6,075 dan angka (sig) 0,000 < 0,05. Jadi, dapat diartikan terima H1 dan tolak H0. Employee performance tidak terbukti signifikan dengan pengaruh employee well-being karena nilai (sig) $>0,05$.

\section{Uji Determinasi}

Tabel 3 menunjukkan nilai Adj. $R$ Square sebesar 0,533 atau 53,3\%. Variabel independen pada penelitian ini menjelaskan sebanyak 53,3\% terhadap variabel dependen, sedangkan sisanya $42,7 \%$ dijelaskan oleh variabel independen lain di luar model regresi. 
Ariesto Patria Sabil. Pengaruh Employee Well-being dan Job Satisfaction terhadap Employee Performance

\section{Pengaruh Employee Well-being terhadap Employee Performance}

Employee performance tidak terbukti dipengaruhi oleh employee well-being. Hasil penelitian menunjukkan bahwa perusahaan kurang bisa memberikan kompensasi kepada karyawan baik itu berupa uang, fasilitas kerja, maupun jaminan kesehatan dan lainnya. Penelitian ini bertentangan dengan temuan employee well-being memengaruhi employee performance oleh Wadhawan (2016), Jalali \& Heidari (2016), dan Kundi et al. (2020) bahwa kesejahteraan memberikan motivasi kepada karyawan untuk meningkatkan kinerjanya dengan tujuan memelihara dan meningkatkan kondisi fisik dan psikis karyawan agar prestasi kerjanya dapat meningkat. Perusahaan dapat melakukan koreksi terhadap bagaimana memerlakukan karyawan perlu dikaji ulang agar dapat membawa dampak yang baik bagi kinerja karyawan yang dapat meningkatkan kinerja perusahaan di masa depan.

\section{Pengaruh Job Satisfaction terhadap Employee Performance}

Employee performance terbukti dipengaruhi oleh job satisfaction. Nilai job satisfaction yang positif signifikan menunjukkan adanya pengaruh bagaimana karyawan merasa puas dan nyaman terhadap pekerjaan yang mereka terima. Artinya, perusahaan telah berhasil menciptakan kenyamanan dan kepuasan terhadap pekerjaan karyawan. Kemudian, penelitian ini sejalan dengan temuan job satisfaction memengaruhi employee performance oleh Permadi et al. (2018) dan Mandala \& Dihan (2018) bahwa seseorang dengan tingkat kepuasan kerja yang tinggi menunjukkan sikap yang positif terhadap pekerjaannya, sebaliknya seseorang yang tidak puas dengan pekerjaannya menunjukkan sikap negatif terhadap pekerjaannya. Perusahaan perlu berupaya menjaga dan meningkatkan bagaimana memberikan kenyamanan bekerja kepada yang membawa dampak yang positif terhadap kinerja.

\section{KESIMPULAN}

Penelitian ini menghasilkan kesimpulan bahwa employee well-being tidak memiliki pengaruh terhadap employee performance dan job satisfaction memiliki pengaruh yang signifikan terhadap employee performance. Job satisfaction memegang peranan bagaimana kenyamanan dalam bekerja dapat meningkatkan produktifitas. Untuk dapat meningkatkan kinerja karyawan, variabel job satisfaction direkomendasikan untuk diperhatikan guna meningkatkan kinerja perusahaan secara general.

Keterbatasan dari penelitian ini adalah penggunaan variabel dependen yang kurang bervariasi, sehingga kurang bisa memberikan gambaran jelas dan menyeluruh mengenai faktor apa saja yang memengaruhi kinerja karyawan. Hasil penelitian ini diharapkan dapat bermanfaat bagi PT. PAL (Persero) untuk mengetahui langkah apa yang dapat ditempuh untuk meningkatkan kinerja karyawan mereka dalam rangka meningkatkan kinerja perusahaan. Untuk penelitian selanjutnya, penggunaan variabel lain seperti mentoring, evaluasi, dan demografi dapat dipertimbangkan baik itu untuk penelitian dengan objek yang sama maupun berbeda.

\section{DAFTAR PUSTAKA}

Badriyah, M. (2015). Manajemen Sumber Daya Manusia. Bandung: CV Pustaka Setia.

Çekmecelioğlu, H. G., Günsel, A., \& Ulutaş, T. (2012). Effects of Emotional Intelligence on Job Satisfaction: an Empirical Study on Call Center Employees. Procedia - Social an Behavioral Sciences, 58(June), 363-369. (https://doi.org/10.1016/j.sbspro.2012.09.1012)

Damayanti, R., Hanafi, A., \& Cahyadi, A. (2018). Pengaruh Kepuasan Kerja terhadap Kinerja Karyawan (Studi Kasus Karyawan Non Medis Rs Islam Siti Khadijah Palembang). Ilmiah Manajemen Bisnis dan Terapan, 2, 75-86.

Dedik, T. I. (2019). Pengembangan Manajemen Sumber Daya Manusia Berbasis Kompeteni Guna Meningkatkan Kinerja Pegawai. Jurnal Perkeretaapian Indonesia, III(2), 93-101. 
Fachreza, Musnadi, S., \& Majid, M. S. A. (2018). Pengaruh Motivasi Kerja, Lingkungan Kerja, dan Budaya Organisasi terhadap Kinerja Karyawan dan Dampaknya pada Kinerja Bank Aceh Syariah di Kota Banda Aceh. Jurnal Magister Manajemen, 2(1), 115-122.

Hasibuan, M. S. P. (2016). Manajemen Sumber Daya Manusia (Revisi). Jakarta: PT Bumi Aksara.

Hustia, A. (2020). Pengaruh Motivasi Kerja, Lingkungan Kerja dan Disiplin Kerja terhadap KinerjaKaryawan Pada Perusahaan WFO Masa Pandemi. Jurnal Ilmu Manajemen, 10(1), 8191. (https://doi.org/10.32502/jimn.v10i1.2929)

Jalali, Z., \& Heidari, A. (2016). The Relationship between Happiness, Subjective Well-Being, Creativity and Job Performance of Primary School Teachers in Ramhormoz City. International Education Studies, 9(6), 45-60. (https://doi.org/10.5539/ies.v9n6p45)

Kundi, Y. M., Aboramadan, M., Elhamalawi, E. M. I., \& Shahid, S. (2020). Employee Psychological Well-Being And Job Performance: Exploring Mediating And Moderating Mechanisms. International Journal of Organizational Analysis, 29(3), 736-754. (https://doi.org/10.1108/IJOA-05-2020-2204)

Kundi, Y. M., Ikramullah, M., Iqbal, M. Z., \& Ul-Hassan, F. S. (2017). Affective Commitment as Mechanism behind Perceived Career Opportunity and Turnover Intentions with Conditional Effect of Organizational Prestige. Journal of Managerial Sciences, 11(03), 65-82. (http://www.qurtuba.edu.pk/jms/JMS Special Edition/3 FMM/05 (AIC-FMM 2017)

Ni'mah, I. (2016). Analisis Kesejahteraan Karyawan Outsourcing dalam Perspektif Karyawan PT Spirit Krida Indonesia. Jurnal Ekonomi Syariah, 4(2), 300-317.

Mandala, E. A., \& Dihan, F. N. (2018). Pengaruh Kecerdasan Emosional dan Kecerdasan Spiritual Pada Kepuasan Kerja yang Berdampak Terhadap Kinerja Karyawan PT. Madu Baru Bantul, Yogyakarta. Kajian Bisnis STIE Widya Wiwaha, 26(1), 13-29. (https://doi.org/10.32477/jkb.v26i1.262)

Masyitah, E \& Harahap, K. K. S. (2018). Analisis Kinerja Keuangan Menggunakan Rasio Likuiditas dan Profitabilitas. Jurnal Akuntansi dan Keuangan Kontemporer, 14(1), 16-27.

Maulidiyah, N. N., Roifah, T. N., \& Armanto, N. (2021). Kompensasi dan Kepuasan Kerja sebagai Alternatif Peningkatan Kinerja Karyawan. Jurnal Al-Idarah, 2(1), 41-48.

Muayyad, D. M., \& Gawi, A. I. O. (2017). Pengaruh Kepuasan Kerja terhadap Produktivitas Kerja Pegawai Bank Syariah X Kantor Wilayah II. Jurnal Manajemen dan Pemasaran Jasa, 9(1), 7584. (https://doi.org/10.25105/jmpj.v9i1.1396)

Permadi, I. K. O., Landra, N., \& Kusuma, I Gusti Agung Eka Teja Sudja, I. N. (2018). The Impact Of Compensation And Work Environment Towards Job Satisfaction To Affect The Employee Performances. International Journal of Management and Commerce Innovations, 6(2), 12481258.

Purba, B. (2019). Analisis Pengaruh Kesejahteraan Karyawan terhadap Semangat Kerja Karyawan pada PT. Asuransi Jiwasraya (Persero) Medan. Jurnal Manajemen Dan Bisnis, 18(2), 150-162.

Qustolani, A. (2017). Pengaruh Kepuasan Kerja, Keadilan Prosedural dan Kompensasi terhadap Kinerja Karyawan. Jurnal Ilmiah Manajemen \& Akuntansi, 4(9), 121-129. 
Ariesto Patria Sabil. Pengaruh Employee Well-being dan Job Satisfaction terhadap Employee Performance

Rizky, T. R., \& Sadida, N. (2019). Hubungan Antara Job Insecurity dan Employee Well Being Pada Karyawan Yang Bekerja di Perusahaan yang Menerapkan PHK di DKI Jakarta. Jurnal EMPATI, 8(1), 329-335.

Robbins, S., \& Mary, C. (2012). Management (eleventh). New Jersey: Pearson Education Limited.

Sadida, N., \& Fitria, N. (2018). Analisis Kesejahteraan Psikologis Karyawan dan Kualitas Interaksi Bawahan Berdasarkan Kepribadian Atasan. Humanitas, 15(1),72-85. (https://doi.org/10.26555/humanitas.v15i1.5328)

Saleem, H. (2015). The Impact of Leadership Styles on Job Satisfaction and Mediating Role of Perceived Organizational Politics. Procedia - Social and Behavioral Sciences, 172, 563-569. (https://doi.org/10.1016/j.sbspro.2015.01.403)

Sari, W. P. (2020). Job Satisfaction and Job Performance Dalam Konteks Komunikasi Organisasi. Jurnal Muara Ilmu Ekonomi Dan Bisnis, 4(1), 29-38. (https://doi.org/10.24912/jmieb.v4i1.7537 2021)

Subardjono, S. (2017). Pengaruh Kepemimpinan terhadap Produktivitas Kerja Pegawai pada Dinas Pendidikan Nasional (Disdiknas) dan Kebudayaan Kabupaten Oku Timur. Jurnal AKTUAL, 15(1), 1. (https://doi.org/10.47232/aktual.v15i1.8)

Sugiyono. (2017). Metode Penelitian Kuantitatif, Kualitatif, dan R\&D. Bandung: Alfabeta, CV

Sugiyono. (2018). Metode Penelitian Kuantitatif. Bandung: Alfabeta

Sujati, Y. G. G. (2018). Kepuasan Kerja: Arti Penting, Faktor-Faktor Yang Mempengaruhi dan Implikasinya Bagi Organisasi. Jurnal Pendidikan Ekonomi, 6(1), 33-45.

Wadhawan, K. (2016). Psychological Well-Being as a Predictor to Job Performance and Job Satisfaction. International Journal of Academic Research and Development, 1(3), 3-5. 